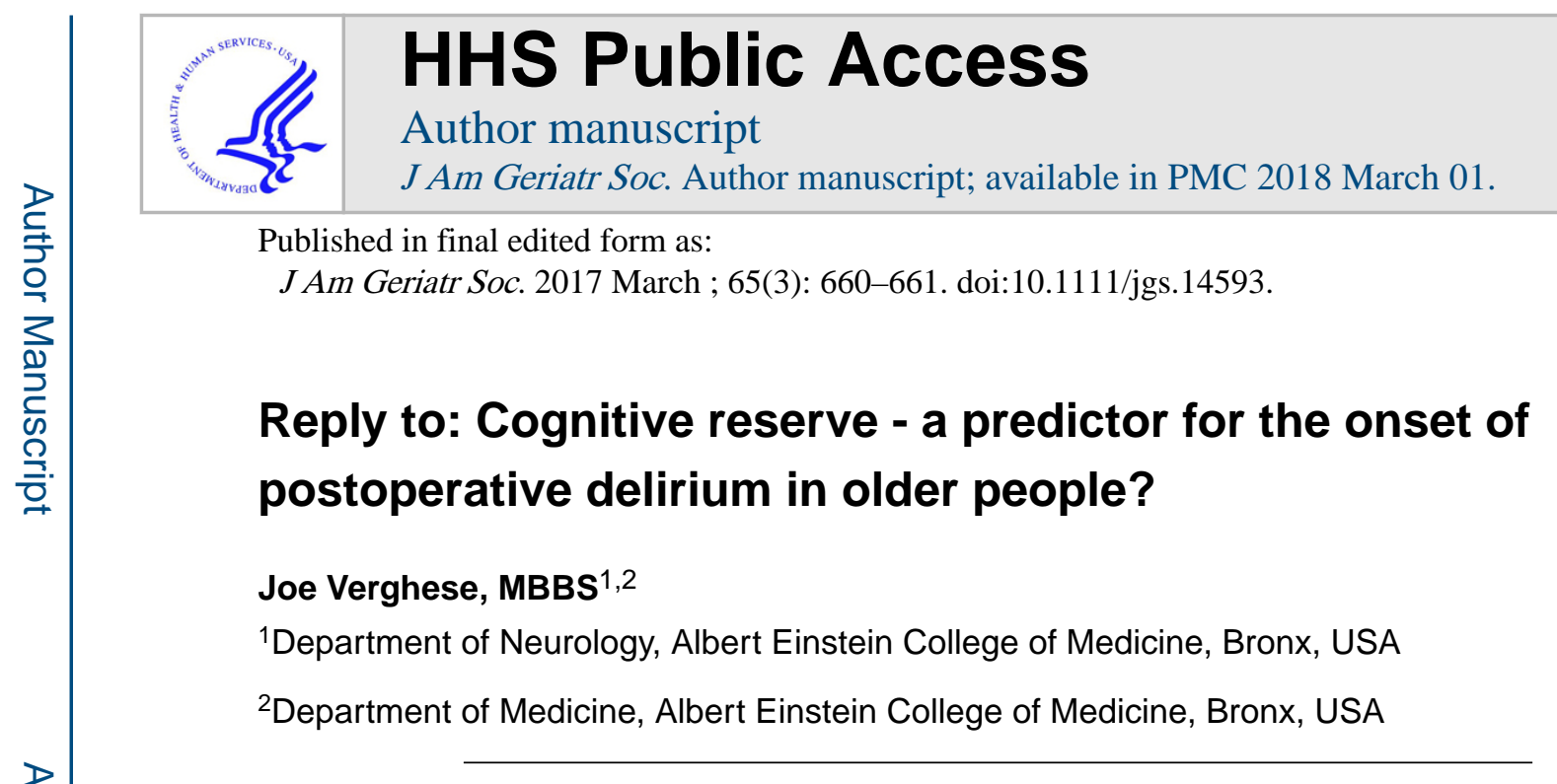

\begin{abstract}
Dear Editor, I appreciate Zhu and colleagues' comments on our report that higher levels of cognitive reserve, measured using participation in cognitive leisure activities, reduced risk and severity of post-operative delirium in older surgical patients. ${ }^{1,2}$ They suggest that muscle function could not only be a target for delirium preventive strategies but also that muscle function could serve as a cognitive reserve measure. The concept of cognitive reserve postulates that some individual characteristics help maintains cognitive function in the face of accumulating brain pathology. ${ }^{3}$ Classical definitions of cognitive reserve incorporate both passive and active mechanisms. ${ }^{3}$ Early work proposed that higher cognitive reserve provides an anatomic buffer (also termed brain reserve) by which greater neuronal or synaptic loss secondary to brain injury or pathology can be sustained before manifesting clinical symptoms. ${ }^{3,4}$ In active models, cognitive reserve is thought to cope with brain damage by actively utilizing various mechanisms such as recruiting pre-existing cognitive networks, improving efficiency of brain processing, or by enlisting compensatory brain networks. ${ }^{3}$ Activities that enhance muscle function may have modest effects on improving or maintaining cognitive function in aging, ${ }^{5}$ however, this association does not equate to being a good measure of cognitive reserve. Under both passive and active cognitive reserve models, ${ }^{3}$ muscle structure and biology are distal to the underlying cognitive processes and brain substrates that may more directly contribute to cognitive reserve. Hence, while I agree that leisure activities that increase cognitive reserve should be explored as a delirium preventive strategy, I do not agree that muscle function is a good proxy for characterizing cognitive reserve. ${ }^{2}$
\end{abstract}

\footnotetext{
Corresponding author and reprint requests: Joe Verghese, M.D., Division of Cognitive \& Motor Aging, Saul R Korey Department of Neurology, Albert Einstein College of Medicine, 1165 Morris Park Avenue, Rousso 301, Bronx, New York 10461, USA. Tel: 718 430 3808. Fax: 718430 3829. joe.verghese@einstein.yu.edu.

Conflict of Interest: None

Funding: None

Authors contribution: JV was responsible for study concept and design, analysis and interpretation of data, and preparation of manuscript.

Sponsors role: N/A.
} 


\section{Conflict of Interest Disclosures}

\begin{tabular}{|l|c|c|}
\hline $\begin{array}{l}\text { Elements of } \\
\text { Financial/Personal } \\
\text { Conflicts }\end{array}$ & \multicolumn{2}{|c|}{ *Author 1 } \\
\hline & Yerghese & No \\
\hline Employment or Affiliation & & $\mathrm{X}$ \\
\hline Grants/Funds & $\mathrm{x}$ & \\
\hline Honoraria & & $\mathrm{x}$ \\
\hline Speaker Forum & & $\mathrm{x}$ \\
\hline Consultant & & $\mathrm{x}$ \\
\hline Stocks & & $\mathrm{x}$ \\
\hline Royalties & & $\mathrm{x}$ \\
\hline Expert Testimony & & $\mathrm{x}$ \\
\hline Board Member & & $\mathrm{x}$ \\
\hline Patents & & $\mathrm{x}$ \\
\hline Personal Relationship & & $\mathrm{x}$ \\
\hline
\end{tabular}

For "yes" $\times$ mark(s): give brief explanation below: JV received funding support from National Institute on Aging grants (R01 AG039330, RO1AGO44007, AGO44829 and R01AG036921).

\section{REFERENCES}

1. Tow A, Holtzer R, Wang C, et al. Cognitive Reserve and Postoperative Delirium in Older Adults. J Am Geriatr Soc. 2016; 64:1341-1346. [PubMed: 27321616]

2. Zhu B, Jiang R-Y, Yang C. Cognitive reserve - a predictor for the onset of postoperative delirium in older people? J Am Geriatr Soc. In press.

3. Stern Y. Cognitive reserve in ageing and Alzheimer's disease. Lancet Neurol. 2012; 11:1006-1012. [PubMed: 23079557]

4. Katzman R. Education and the prevalence of dementia and Alzheimer's disease. Neurology. 1993; 43:13-20. [PubMed: 8423876]

5. Snowden M, Steinman L, Mochan K, et al. Effect of exercise on cognitive performance in community-dwelling older adults: review of intervention trials and recommendations for public health practice and research. J Am Geriatr Soc. 2011; 59:704-716. [PubMed: 21438861] 